\title{
The transcriptome of zinc deficient maize roots and its relationship to DNA methylation loss
}

\author{
Svenja Mager, Brigitte Schönberger and Uwe Ludewig ${ }^{*}$ (D)
}

\begin{abstract}
Background: Zinc (Zn) is an essential micronutrient of all organisms. Deficiency of zinc causes disturbance in crucial plant functions, as a high number of enzymes, including transcription factors, depend on zinc for proper performance. The plant responses to zinc deficiency are associated with increased high affinity Zn uptake and translocation, as well as efficient usage of the remaining zinc, but have not been characterized in molecular detail in maize.

Results: The high affinity transporter genes $Z m Z I P 3,4,5,7$ and 8 and nicotianamine synthases, primarily ZmNAS5, were identified as primary up-regulated in maize roots upon prolonged Zn deficiency. In addition to downregulation of genes encoding enzymes involved in pathways regulating reactive oxygen species and cell wallrelated genes, a massive up-regulation of the sucrose efflux channel genes SWEET13a,c was identified, despite that in -Zn sugar is known to accumulate in shoots. In addition, enzymes involved in DNA maintenance methylation tended to be repressed, which coincided with massively reduced DNA methylation in Zn-deficient roots. Reduced representation bisulfate sequencing, which revealed base-specific methylation patterns in $\sim 14 \%$ of the maize genome, identified a major methylation loss in -Zn, mostly in transposable elements. However, hypermethylated genome regions in -Zn were also identified, especially in both symmetrical cytosine contexts. Differential methylation was partially associated with differentially expressed genes, their promoters, or transposons close to regulated genes. However, hypomethylation was associated with about equal number of up- or down-regulated genes, questioning a simple mechanistic relationship to gene expression.

Conclusions: The transcriptome of Zn-deficient roots identified genes and pathways to cope with the deficiency and a major down-regulation of reactive oxygen metabolism. Interestingly, a nutrient-specific loss of DNA methylation, partially related to gene expression in a context-specific manner, may play a role in long-term stress adaptation.
\end{abstract}

Keywords: Zinc, DNA methylation, Maize, Gene expression, Genome stability, Transposable elements

\section{Background}

Zinc $(\mathrm{Zn})$ is an essential micronutrient needed by every organism on earth. It is an important cofactor of a high number of transcription factors and enzymes in plants [1]. Zinc can function as structural component aiding in appropriate protein folding and as a catalytic component, enabling or enhancing the reactions performed by enzymes. Additionally, zinc is also needed for proper

\footnotetext{
* Correspondence: uludewig@uni-hohenheim.de

Institute of Crop Science, Nutritional Crop Physiology, University of

Hohenheim, Fruwirthstr. 20, 70593 Stuttgart, Germany
}

membrane integrity and takes part in RNA and DNA metabolism, as well as gene expression regulation. It is further involved in detoxification of superoxide radicals and synthesis of phytohormones [1-4]. Considering these many functions of zinc in plants, it is not surprising that plants suffer strongly from prolonged zinc deficiency $(-\mathrm{Zn})$ and have developed a range of coping mechanisms. Zn deficiency is especially widespread in areas of calcareous, sandy or peat soils. Due to their high $\mathrm{pH}$, which causes $\mathrm{Zn}$ adsorption to clay or calcium carbonate, the bioavailable $\mathrm{Zn}$ that can be absorbed by the roots remains limited, despite substantial $\mathrm{Zn}$ content in

(c) The Author(s). 2018 Open Access This article is distributed under the terms of the Creative Commons Attribution 4.0 International License (http://creativecommons.org/licenses/by/4.0/), which permits unrestricted use, distribution, and 
such soils. In waterlogged soils, effecting world-wide flooded rice production, the risk for $\mathrm{Zn}$ deficiency is heightened due to zinc forming sparingly soluble compounds in the oxidized rhizosphere [5]. All in all, it is estimated that about $50 \%$ of cereal crop agricultural soils are potentially zinc deficient [5].

In maize, $\mathrm{Zn}$ deficiency leads to stunted growth and morphological abnormalities, such as lower vascular bundle proportion and higher stomatal density, among changes in physiology, such as decreased net photosynthesis and lowered stomatal conductance [6]. It is well-established that under Zn deficiency, zinc transporter genes from the ZIP (Zrt/Irt-like proteins) family are up-regulated to facilitate the uptake of traces of remaining zinc $[2,7,8]$, but in maize, these genes were only marginally up-regulated in $-\mathrm{Zn}$ in shoots and roots [9]. Furthermore, in a $\mathrm{Zn}$ tolerant genotype, $\mathrm{Zn}$ transporter genes ZmZIP1, ZmZIP4 and ZmIRT1 were moderately up-regulated by $Z$ n deficiency, but not in a sensitive genotype [10].

But not only plants need a sufficient amount of zinc, also animals and humans are negatively affected by zinc deficiency. Among humans, especially widespread in developing countries, zinc deficiency concerns over 2 billion people. Zinc in humans is needed by the immune system, for DNA synthesis and RNA transcription, as well as in cell division and prevention of apoptosis [11]. Health consequences of zinc deficiency range from weight loss over emotional disorder to impairment of the immune system, to mention only some [12]. In respect to that, sufficient intake of zinc via crop products helps to alleviate this nutritional disorder. One approach for achieving this is biofortification, to increase the nutritional value of important crop plants by breeding. Knowledge about plant mechanisms for using zinc or coping with zinc deficiency is imperative. Substantial knowledge on how plants handle zinc is available, although molecular mechanisms of zinc homeostasis in plants are still fragmentary [2]. More recently, DNA methylation changes were reported for many stresses, including nutrient stresses. In various cases, for example phosphorus starvation, gene expression changes were correlated with DNA methylation differences, especially in the dynamic, non-symmetrical cytosine context [13, 14]. This methylation context, also responsible for de-novo DNA methylation, is dependent on the RNA-directed DNA methylation (RdDM) pathway, in which sRNAs play an important role. In this pathway, plant-specific DNA-dependent RNA polymerases produce short RNA transcripts, from which double-stranded RNAs (dsRNAs) are produced by an RNA-dependent RNA polymerase. In turn, these dsRNAs are then cleaved by a protein called dicer-like 3 (DCL3) to form 21 to 24 nucleotide sRNAs, which are then incorporated into argonaute 4 (AGO4). This complex then guides DNA methylation with sequence information from the RNAs [15-17].

We hypothesized that major gene categories that have been identified as regulated under $\mathrm{Zn}$ deficiency in model plants are also similarly regulated in $\mathrm{Zn}$-deficient maize roots. Maize-specific genes, however, might also be identified. We therefore performed RNA-sequencing on well-supplied and zinc-deficient maize roots. While typical $\mathrm{Zn}$ deficiency response genes were identified, we noted that genes involved in DNA methylation were also affected by $-\mathrm{Zn}$ and therefore quantified the impact of $\mathrm{Zn}$ deficiency on the DNA methylome. DNA methylation in plants is suggested to influence different plant functions, as for example aiding in the pathogen response, genome stability, heterosis, as well as suppression of transposable elements (TEs) and genes [18, 19]. Whether and how DNA methylation is correlated to gene expression under $\mathrm{Zn}$ deficiency is presented and discussed.

\section{Results}

Phenotype and nutrient concentrations of maize plants Phenotypic investigation of control and $-\mathrm{Zn}$ plants showed vigorous growth of control plants, while - Zn plants showed typical Zn deficiency-induced symptoms with strongly stunted growth. The leaf and root size were reduced and chlorotic and necrotic marks on the leaves were visible [3] (Fig. 1a). Nutrient analysis confirmed the $\mathrm{Zn}$ deficiency in shoots of $-\mathrm{Zn}$ plants, whereas iron, which can potentiate reactive oxygen stress and is frequently higher in field conditions under $\mathrm{Zn}$ deficiency, was close to control level (Fig. 1b). Zn was at only $6.9 \mathrm{ppm}$, while control plants contained more than $30 \mathrm{ppm} \mathrm{Zn}$ and sufficient amounts of all other tested nutrients, although the $\mathrm{Zn}$-deficient plants had slightly reduced nitrogen and phosphorus levels (Fig. 1b).

\section{Zinc-deficiency adapted transcriptome}

Root transcriptomes under prolonged $\mathrm{Zn}$ deficiency were then obtained and compared to controls. Of the RNA samples taken from control and $-\mathrm{Zn}$ roots, the alignment rate was higher in controls (91.8\%) compared to $79.6 \%$ in $-\mathrm{Zn}$ (Additional file 1:Table S1). The aligned transcripts were assembled and analyzed for differentially expressed genes. Altogether, 4807 significantly differentially expressed genes (DEGs) were identified between the control and the $-\mathrm{Zn}$ treatment. An almost equal number of genes were up- or down-regulated, namely 2372 and 2434, respectively (Fig. 2a). In contrast to short or mild $\mathrm{Zn}$ deficiencies tested previously [9], several genes coding for zinc uptake systems, $Z m Z I P 3$, ZmZIP4, ZmZIP5, ZmZIP7 and ZmZIP8, were substantially up-regulated (Table 1). Additionally, genes encoding 
a

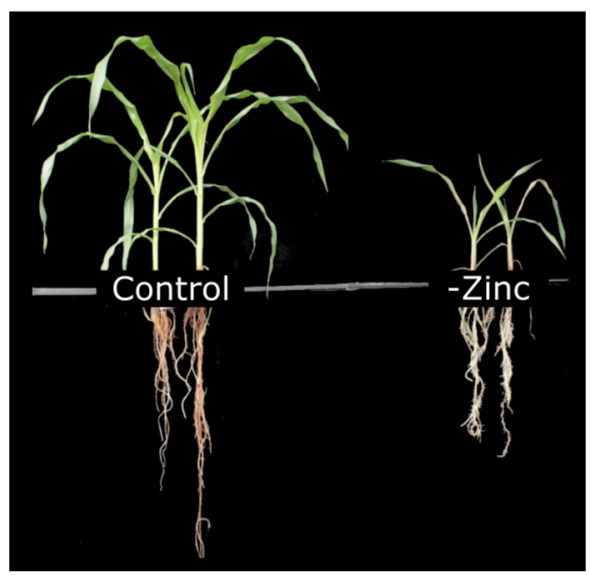

b

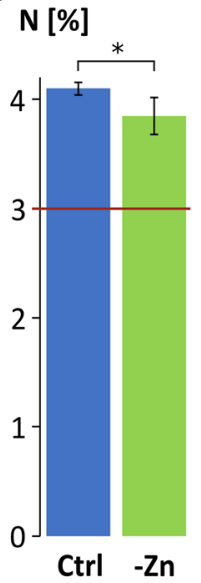

$\mathrm{P}[\%]$

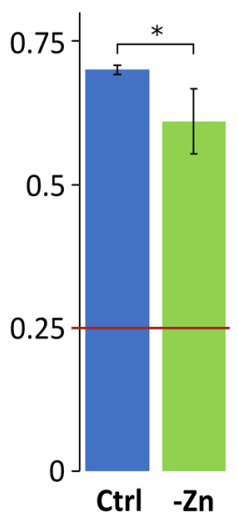

Fe [ppm]



Zn [ppm]

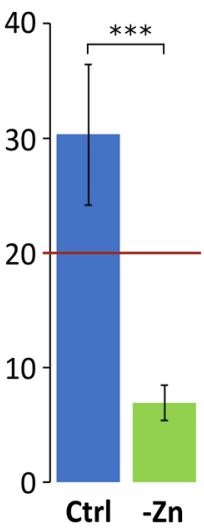

Fig. 1 Plant phenotypes and shoot nutrient concentrations (a) Phenotype of control and -Zn plants at harvest. b Concentrations of $N$, P, Fe and $\mathrm{Zn}$ in control (blue bars) and -Zn (green bars) shoots $(n=3)$. The red lines indicate sufficiency levels for maize

for nicotianamine synthase (NAS), especially the abundant $Z m N A S 5$, were consistently up-regulated during zinc deficiency. NAS synthesizes nicotianamine, which in turn is involved in translocation of heavy metals, as for example zinc and iron, between organs. Zinc is needed for detoxification of superoxide radicals via the copper/ zinc-dependent superoxide dismutase and the transcripts of this enzyme were down-regulated under zinc deficiency, consistent with results from many other plants [3]. Strong down-regulation was also discovered in many peroxidases, where 55 out of the 63 differentially expressed peroxidases were reduced in their expression level (two of them are exemplary shown in Table 1). Carbonic anhydrase, well-known to require $\mathrm{Zn}$ as a co-factor and catalyzing $\mathrm{CO}_{2}$ hydration, was also reduced in $-\mathrm{Zn}$ (Table 1). There was an increase in purple acid phosphatases, which help maintaining inorganic phosphate metabolism and may be used to mobilize $\mathrm{Zn}$ that is in complex with phosphate [20]. Expansins, by contrast, which play roles in plant cell expansion, were down-regulated under $-\mathrm{Zn}$, in agreement with smaller organ sizes in $-Z n$. Interestingly, a strong up-regulation of the sugar efflux transporter genes SWEET13a and $c$, which are involved in phloem loading of sucrose in the leaves [21], was noted (Table 1).

Gene enrichment analysis revealed a strong overrepresentation of down-regulated categories with genes coding for enzymes that are involved in the oxidative stress response, like the before mentioned peroxidases and superoxide dismutases. The three most significant down-regulated GO term categories contained genes involved in the oxidative stress response (Table 2). Despite that the total number of individual up- and down-regulated genes was similar, the down-regulated gene categories were much more pronounced than significantly up-regulated categories, which only comprised a single GO term, which was related to production of secondary metabolites.

Interestingly, several genes coding for maintenance methylation enzymes also tended to be down-regulated, while some demethylating enzymes were up-regulated (Fig. 2b). Genes involved in the RdDM pathway were less consistently regulated, but it is important to note that the expression of (de-)methylation-related genes was altogether relatively low, somewhat questioning the significance of the observed differences.

When comparing differential expression under zinc deficiency with previously analyzed differential expression under nitrogen or phosphorus deficiency [22], we noted a small overlap of genes that were up- or down-regulated under all three deficiencies (344 and 528, respectively, Fig. 2c). A much larger number of genes, however, was specifically associated with individual nutrient deficiencies and these included the genes associated with $-\mathrm{Zn}$ discussed above.

\section{Adaptation of DNA methylation to $\mathrm{Zn}$ deficiency}

The transcriptional data suggested that $-\mathrm{Zn}$ adapted roots might be demethylated, which was experimentally tested by reduced representation bisulfite sequencing of DNA extracted from the same root material, from which nutrient analyses and RNA-seq profiles were generated. These data provided sequence-specific methylation information for about $14 \%$ of the maize genome $(\sim 18 \%$ of all cytosines) in each sample. The conversion rate after bisulfite treatment for each sample was $>98 \%$ (between 98.41 and $99.18 \%$ ). About $90 \%$ of all cytosines were covered by at least 5 reads in all contexts (Additional file 1 : Figure S1) and mappability was $>48 \%$ (Additional file 1 : 

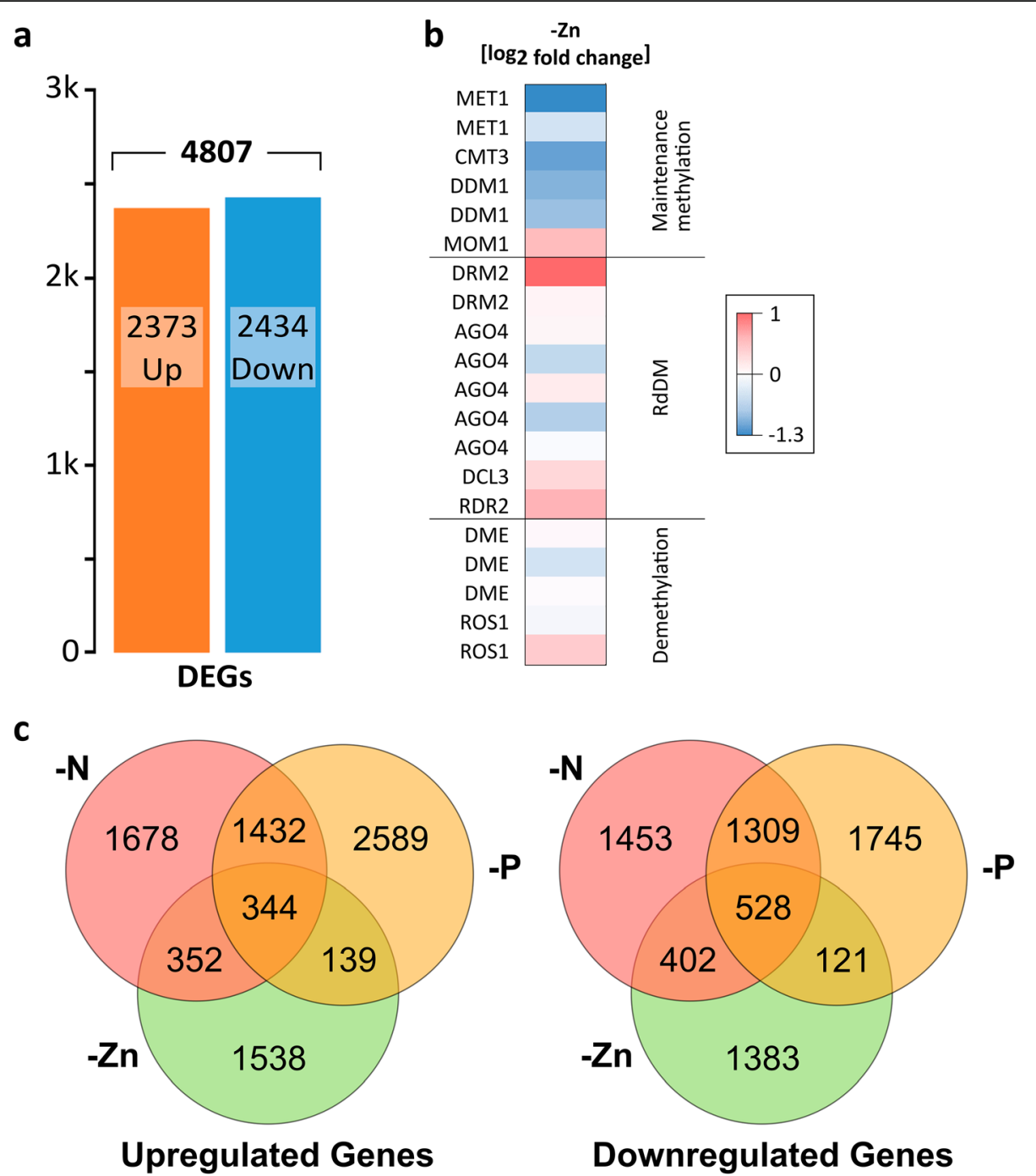

Fig. 2 Differential gene expression in -Zn (a) Number of differentially expressed genes (DEGs, $p<0.05$ ), either up- (orange) or down-regulated (blue) in Zn deficiency. $\mathbf{b}$ Log $_{2}$-fold differences in gene expression of putative genes involved in DNA methylation and demethylation. Blue: down-regulated, red: up-regulated. (c) Overlap of up-regulated (left) and down-regulated (right) genes in different deficiencies (- $\mathrm{Zn},-\mathrm{N},-\mathrm{P})$; nitrogen and phosphorus deficiency data from [22]

Table S2) indicating sufficient coverage and mappability for reliable downstream analyses.

Principal component analysis was performed on the methylation levels of the cytosines of control and $-\mathrm{Zn}$ samples (Figure 3a). The variance of principle component 1 (PC1) explained about $24 \%$ of the total variance and separated the control and $-\mathrm{Zn}$ samples into two groups. PC2 was apparently mainly due to variances between the replicates of $-\mathrm{Zn}$. We also compared our dataset to data from $-\mathrm{N}$ and $-\mathrm{P}$ treated maize roots [22], which revealed that the methylome samples for each nutrient deficiency were separated mainly by PC1. This variance explained about $15 \%$ of the total variance between the three treatments.
A massive loss of methylation in the $\mathrm{CG}$ and $\mathrm{CHG}$ contexts $(\mathrm{H}=\mathrm{A}, \mathrm{T}$ or $\mathrm{C})$ in $-\mathrm{Zn}$ was found (Fig. $3 \mathrm{~b})$. In the control, $26.6 \%$ of all cytosines in the CG context were methylated, whereas in - $\mathrm{Zn}$ samples, only about half as many CGs were methylated (13.2\%). There was also a significant loss of methylation for - $\mathrm{Zn}$ samples in the CHG context, where $9.7 \%$ were methylated in $-\mathrm{Zn}$, compared to $18.7 \%$ in control samples. The $\mathrm{CHH}$ context was almost unaffected by the deficiency. Cytosines in this context showed only very low methylation, as already found in our previous analysis [22]. This methylation level was slightly further reduced in - $\mathrm{Zn}$ samples, from $1.26 \%$ in control to $1.06 \%$ in $-\mathrm{Zn}$.

The methylation distribution across whole chromosomes was analyzed by DMRcaller (Fig. 3c). The 
Table 1 Examples of differentially expressed genes under Zn deficiency

\begin{tabular}{|c|c|c|c|c|}
\hline Gene ID & Annotation & FPKM Control & FPKM -Zn & $\log _{2} \mathrm{FC}$ \\
\hline GRMZM2G111300 & ZIP-type metal cation transporter ZmZIP4 & 68.3 & 255.7 & 1.90 \\
\hline GRMZM2G045849 & ZIP-type metal cation transporter ZmZIP3 & 52.9 & 106.0 & 1.02 \\
\hline GRMZM2G064382 & ZIP-type metal cation transporter ZmZIP5 & 8.3 & 154.6 & 4.21 \\
\hline GRMZM2G015955 & ZIP-type metal cation transporter ZmZIP7 & 114.9 & 195.9 & 0.77 \\
\hline GRMZM2G047762 & ZIP-type metal cation transporter ZmZIP1-related & 26.2 & 134.9 & 2.37 \\
\hline GRMZM2G093276 & ZIP-type metal cation transporter ZmZIP8 & 20.6 & 119.6 & 2.54 \\
\hline GRMZM2G106928 & Superoxide dismutase & 58.0 & 25.6 & -1.18 \\
\hline GRMZM2G175728 & Superoxide dismutase & 11.7 & 3.2 & -1.89 \\
\hline GRMZM2G410175 & Peroxidase & 66.6 & 0.9 & -6.3 \\
\hline GRMZM2G048474 & Peroxidase & 76.1 & 3.5 & -4.4 \\
\hline GRMZM2G478568 & Nicotianamine synthase ZmNAS3 & 19.2 & 45.1 & 1.23 \\
\hline GRMZM2G050108 & Nicotianamine synthase ZmNAS5 & 35.5 & 186.7 & 2.40 \\
\hline GRMZM2G312481 & Nicotianamine synthase ZmNAS8 & 0.4 & 2.2 & 2.64 \\
\hline GRMZM2G385200 & Nicotianamine synthase ZmNAS1 & 1.5 & 8.5 & 2.49 \\
\hline GRMZM2G034956 & Nicotianamine synthase ZmNAS10 & 5.0 & 0.4 & -3.60 \\
\hline GRMZM2G348512 & Carbonic Anhydrase 2 & 230.8 & 125.3 & -0.88 \\
\hline GRMZM2G046924 & Carbonic Anhydrase 1 & 89.2 & 54.1 & -0.72 \\
\hline GRMZM2G073860 & Purple acid phosphatase 10 & 7.8 & 17.9 & 1.19 \\
\hline GRMZM2G134054 & Purple acid phosphatase 15 & 3.90 & 10.9 & 1.48 \\
\hline GRMZM2G133322 & sugar efflux transporter ZmSWEET12a & 1.2 & 78.3 & 6.07 \\
\hline GRMZM2G060974 & sugar efflux transporter ZmSWEET3b & 17.5 & 0.3 & -5.77 \\
\hline GRMZM2G173669 & sugar efflux transporter ZmSWEET13a & 75.2 & 1229.6 & 4.03 \\
\hline GRMZM2G179349 & sugar efflux transporter ZmSWEET13C & 7 & 79.2 & 3.51 \\
\hline GRMZM2G139834 & Nodulin MtN21 family protein & 29.1 & 2.6 & -3.51 \\
\hline GRMZM2G467893 & Nodulin family protein & 11.1 & 128.7 & 3.54 \\
\hline GRMZM2G001035 & vacuolar iron transport-like & 70.3 & 1.7 & -5.34 \\
\hline GRMZM2G173826 & Expansin-A12 precursor EXP11 & 15.4 & 1.7 & -3.16 \\
\hline GRMZM2G450546 & Expansin-A19 precursor EXP11 & 6.3 & 0.3 & -4.51 \\
\hline GRMZM2G021427 & Expansin-B3 precursor EXPB2 & 20.6 & 2.3 & -3.15 \\
\hline \multirow[t]{2}{*}{ GRMZM2G327266 } & Expansin-B11 precursor & 39.8 & 4 & -3.31 \\
\hline & EXPB4 & & & \\
\hline
\end{tabular}

FPKM Fragments per kilobase of transcript per million mapped reads, $\log _{2}$ FC $\log _{2}$ (FPKM -Zn/FPKM Control)

methylation level in the three different cytosine contexts in chromosome 1 is shown as a representative example. Especially in the CG and CHG context, the profiles show that the methylation was higher at the centromeric region and decreased towards the ends of the chromosomes. Again, the $\mathrm{CHH}$ context formed an exception, as here the higher methylation at the centromere was almost not visible. The reduction of CG and CHG methylation was relatively uniform, though most methylation seemed to be lost at centromeric and pericentromeric regions, reducing the comparably higher overall methylation level in centromeric regions. In all chromosomes, the reduced methylation in - $\mathrm{Zn}$ was less pronounced in the $\mathrm{CHH}$ context than in the other two contexts.
Even though a lot of methylation was lost in the deficiency samples, a similar fraction of the total number of methylated cytosines was found in each context (Fig. 3d). This showed that the same relative amount of methylation is lost in each context.

Individual base methylation changes are currently thought to have little functional relevance, so only differentially methylated regions (DMRs) were considered. We defined DMRs as regions between 50 and $500 \mathrm{bp}$ that contain at least 4 cytosines, more than 3 reads per cytosine were required, which differed in methylation by more than $40 \%$ and a p-cutoff value of $\leq 0.01 .2762$ DMRs were identified in total, with most DMRs in the CG context (Table 3). In the CHG context, 402 DMRs 
Table 2 Over-representation of gene ontology (GO) categories in -Zn roots

\begin{tabular}{|c|c|c|l|c|}
\hline GO Term & $\begin{array}{c}\text { GO } \\
\text { Domain }\end{array}$ & $\begin{array}{c}\text { Number } \\
\text { of Genes }\end{array}$ & \multicolumn{1}{|c|}{ Description } & Z-score \\
\hline GO:0016684 & F & 62 & oxidoreductase activity, acting on peroxide as acceptor & -6.5 \\
GO:0004601 & F & 62 & peroxidase activity & -6.5 \\
GO:0016209 & F & 66 & antioxidant activity & -6.2 \\
GO:0005618 & C & 140 & cell wall & -5.2 \\
GO:0030312 & C & 143 & external encapsulating structure & -4.9 \\
GO:0006979 & P & 101 & response to oxidative stress & -4.7 \\
GO:0044262 & P & 133 & cellular carbohydrate metabolic process & -4.3 \\
GO:0044264 & P & 45 & cellular polysaccharide metabolic process & -4.2 \\
GO:0005507 & F & 74 & copper ion binding & -4.2 \\
GO:0005856 & C & 41 & cytoskeleton & -4.1 \\
GO:0005975 & P & 240 & carbohydrate metabolic process & -4 \\
GO:0034637 & P & 55 & cellular carbohydrate biosynthetic process & -3.8 \\
GO:0016051 & P & 58 & carbohydrate biosynthetic process & -3.7 \\
GO:0043232 & C & 141 & intracellular non-membrane-bounded organelle & -3.6 \\
GO:0043228 & C & 141 & non-membrane-bounded organelle & -3.6 \\
GO:0044459 & C & 114 & plasma membrane part & -3.6 \\
GO:0009505 & C & 66 & plant-type cell wall & -3.5 \\
GO:0016705 & F & 105 & oxidoreductase activity, acting on paired donors, with & incorporation or reduction of molecular oxygen \\
\hline
\end{tabular}

Bonferroni multi-test adjusted Parametric Analysis of Gene Set Enrichment (PAGE) of $\log _{2}$ fold-change of DEGs. GO domain: $\mathrm{F}$, molecular function; C, cellular compartment; $\mathrm{P}$, biological process. Top 18 categories are shown. Color code: Blue $=$ underrepresentation, orange = overrepresentation of gene category in $-\mathrm{Zn}$

were identified. By contrast, in the $\mathrm{CHH}$ context only 3 DMRs were found. With less strict cutoff values for DMRs (minimum of 3 cytosines, at least 3 reads per cytosine and at least $10 \%$ methylation difference) 41 DMRs were identified (Table 3).

As in $-\mathrm{Zn}$ the overall methylation was massively decreased in the CG and CHG contexts, DMRs were preferentially hypomethylated, but hypermethylated regions in $-\mathrm{Zn}$ were also identified. This indicated that in addition to the methylation loss, further de novo methylation in - Zn occurred. In total, about $93-98 \%$ of all DMRs were hypomethylated (Fig. 4a).

DMRs in both CG and CHG contexts were primarily located within TEs, more than 86 and $92 \%$ for CG and CHG, respectively (Fig. $4 \mathrm{~b}$ ). Considering that $85 \%$ of the maize genome is considered to be composed of TEs, this indicates that DMRs in the CHG context were preferentially targeting TEs. Such preference for DMRs in TEs was not apparent in the CG context. Relatively few DMRs were spanning both promoter and genes, with only $1-2 \%$ in both contexts. DMRs located in promoters were also relatively rare, with $2-4 \%$ depending on the context. DMRs in genes amounted up to 9 and $2 \%$ in CG and CHG contexts, respectively.

\section{Correlation between differential DNA methylation and transcriptional changes}

The RRBS and RNA-sequencing data were then analyzed for possible correlations between methylation and gene expression differences. The distribution of TEs, genes, DEGs and DMRs in the entire ten chromosomes of the maize genome is shown in Fig. 5. Centromers [23] are marked with a red line. The enrichment of genes towards the terminal ends of each chromosome arm was associated with more DEGs in -Zn. CG and CHG DMRs, by contrast, were rather uniformly distributed across each chromosome and were preferentially localized in TEs.

Since methylation was measured only in a representative fraction of the genome, but RNA-seq covered all differentially expressed genes, we calculated the percentage of differentially expressed genes containing a DMR in their gene body. The fraction of differentially expressed genes that had DMRs in the $2 \mathrm{~kb}$ region upstream of the gene (putative promoter) was also determined, as well as nearby downstream DMRs (Fig. 6a). In the CG context, 32 of the 423 differentially methylated genes covered by the RRBS were also differentially expressed, amounting for $8 \%$ of the genes with DMRs. In the CHG context, 




only a single gene was differentially methylated and differentially expressed at the same time, comprising only $3 \%$.

To examine the statistical significance of the above observations, we considered only genes that were covered by at least 500 base pairs in the reduced representation methylome. By contrast, no length restriction was applied to differentially methylated TEs for testing the influence on the expression of the closest gene, because many TEs were very short and these were 
Table 3 Number of DMRs resulting from strict and loosened criteria defining a DMR

\begin{tabular}{lll}
\hline & Strict Criteria & Loose Criteria \\
\hline $\mathrm{CG}$ & 2762 & 10,036 \\
$\mathrm{CHG}$ & 402 & 2897 \\
$\mathrm{CHH}$ & 3 & 41 \\
\hline
\end{tabular}

otherwise lost from the analysis. For the CG context, a significant correlation (at 5\% level) of gene expression and the methylation in their promoters or genes themselves was suggested, with $p$-values of 0.023 and 0.005 , respectively (Fig. 6b). On the other hand, there was no significant correlation between differentially methylated TEs and differential expression of the closest gene.

To further examine the relationship between differential methylation and gene expression, scatter plots were applied for differentially methylated TEs whose closest gene was differentially expressed, as well as for differentially expressed genes, which had a DMR in their promoter or gene body (Fig. 6c). The data points are skewed to the left part of the diagram, as methylation was predominantly reduced. Interestingly, differentially methylated promoters/gene bodies and differentially methylated TEs were both in up- or down-regulated genes, without preference for either change. Thus, even though there were significant correlations found for differentially expressed genes/promoters and the gene's expression, gene expression can be repressed or stimulated by demethylation. A similar result was found if all genes were considered for the scatterplots (instead of only significantly differentially expressed ones, Additional file 1: Figure S2).

Among all genes that were differentially expressed and possessed a DMR in their gene body, in their $2 \mathrm{~kb}$ promoter or nearby transposable element, there were several genes that might be causally involved in the response to $\mathrm{Zn}$ deficiency. The position of the DMRs in the gene structure is shown for some differentially expressed gene examples in Fig. 6d. Among the differentially expressed genes discussed in Table 1, expansin genes were prominent and down-regulated under - Zn. A hypomethylation DMR was located in the gene body of expansin11, while a nodulin gene was up-regulated and hypomethylated just upstream of the transcriptional start site. Two examples for differentially methylated TEs near to differentially expressed genes are given in Fig. 6e. Nicotianamine synthase ZmNAS8 was up-regulated and a carbonic anhydrase down-regulated in expression, while each of them was located near a hypomethylated TE. This illustrates that although hypomethylation was dominant, both up- and down-regulation of gene expression occurred upon hypomethylation.

As small RNAs play roles in the RNA -directed DNA methylation pathway, which is especially important for the $\mathrm{CHH}$ methylation, but also for CHG and CG contexts, we speculated that small RNAs might be decreased in the $-\mathrm{Zn}$ samples that had massively lost methylation. This is supported by the observation that -Zn samples contained a much lower ratio of small RNAs to total RNA, which amounted to $1.4 \%$, compared to $9.7 \%$ in the controls (Additional file 1: Figure S3).

\section{Discussion}

The prolonged growth of plants in Zn deficiency caused a range of changes in the roots, including transcriptomic as well as epigenetic changes. The $\mathrm{Zn}$ level in deficient plants $(6.9 \mathrm{ppm})$ was well below the concentration typically considered as sufficient for maize $(20 \mathrm{ppm})$. These stunted plants had similar iron concentrations, but they were slightly reduced in $\mathrm{N}$ and $\mathrm{P}$, probably reflecting secondary metabolic effects from the prolonged $\mathrm{Zn}$ deficiency, but both macroelements were in the sufficiency range. Our further focus was on a representative fraction of the root methylome and its entire transcriptome.

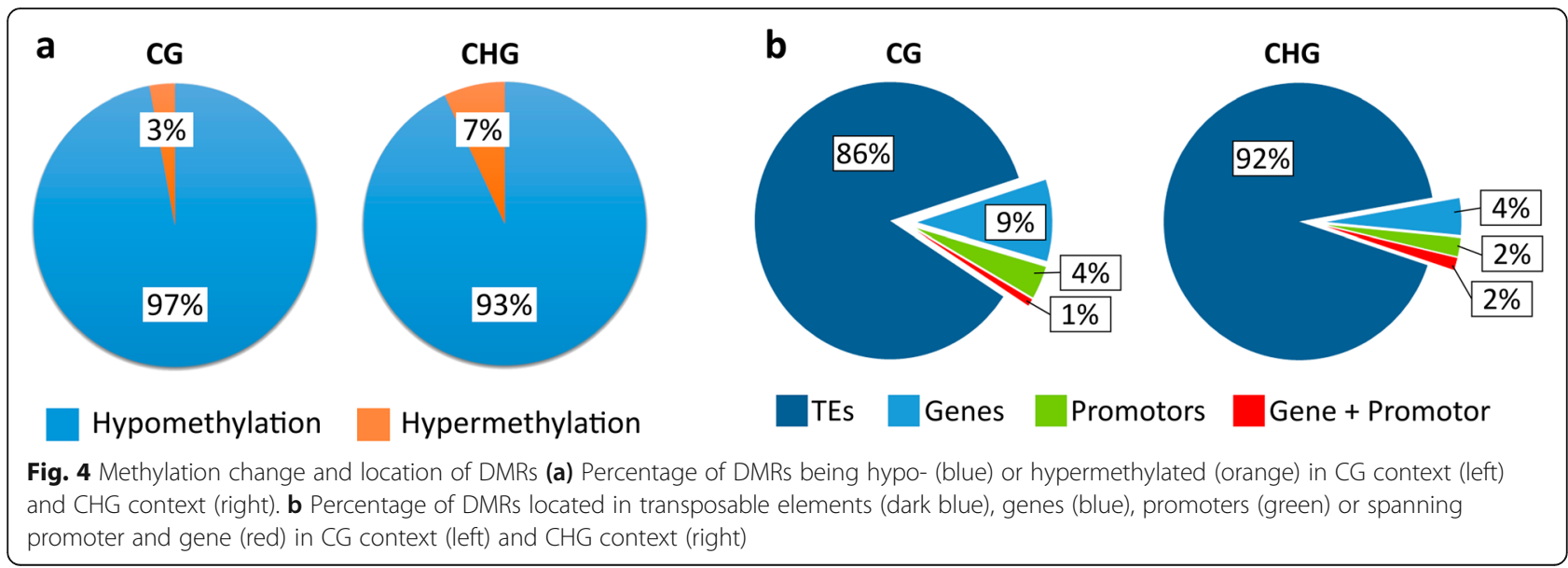




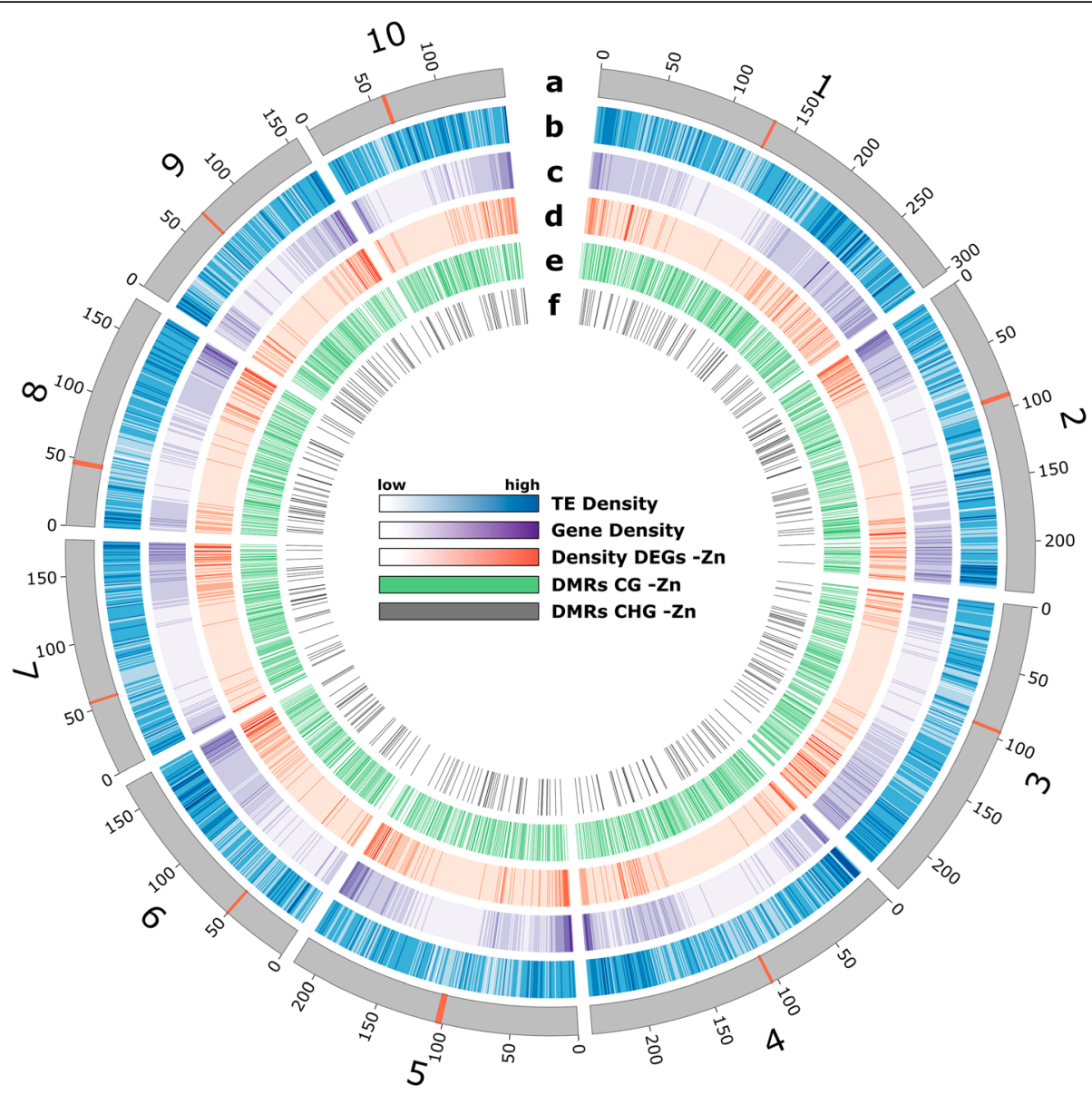

Fig. 5 Distribution of different features across all 10 chromosomes of the B73 genome (a) Chromosomes (grey) with their centromere shown as red band. $\mathbf{b}$ Density of transposable elements (TEs, blue). $\mathbf{c}$ Gene density (violet). $\mathbf{d}$ Density of DEGs in -Zn (red). e Distribution of CG DMRs in -Zn (green). $\mathbf{f}$ Distribution of CHG DMRs in -Zn (dark grey)

\section{The maize root transcriptome upon prolonged $\mathrm{Zn}$ deficiency}

Substantial expression of high affinity transporters for a certain nutrient is a key feature of typical prolonged deficiency, to provide efficient uptake of the small remaining traces of that nutrient. For $\mathrm{Zn}$ deficient roots, substantial up-regulation of zinc transmembrane transporter genes, which were previously found to be only marginally up-regulated by $\mathrm{Zn}$ deficiency in maize shoots and roots [9], was observed. These include $Z m Z I P 3,4,5,7,8$ and a ZIP1-related gene, which were expressed under $-\mathrm{Zn}$ at similar elevated levels, but also nicotianamine synthase (NAS), which is involved in synthesizing the heavy metal chelator nicotianamine [7]. The most prominent gene from this gene family in $-\mathrm{Zn}$ was ZmNAS5, while carbonic anhydrase genes were slightly down-regulated in the - $\mathrm{Zn}$ maize roots, consistent with spinach and rice plants $[24,25]$.

Prolonged nutrient deficiency in roots may create secondary stress, but despite thousands of genes were differentially regulated, the $-\mathrm{Zn}$ transcriptome was consistent with much of the physiological knowledge of $\mathrm{Zn}$ deficiency. The up-regulation of purple acid phosphatase genes under - $\mathrm{Zn}$ in maize was also found in wheat [20]. Similar to results in Arabidopsis [7], some nodulin-like protein coding genes were down-regulated in $-\mathrm{Zn}$. However, here some (uncharacterized) nodulin family genes were also highly up-regulated in the $-\mathrm{Zn}$ maize roots. Similar to $\mathrm{Zn}$-deficient Arabidopsis roots, expansin genes were profoundly down-regulated [7], in agreement with smaller roots. Consistent with the literature is also the strong gene expression loss of superoxide dismutase, peroxidase and other enzyme genes needed for detoxification of reactive oxygen species [3]. Elevated hydrogen peroxide concentrations and insufficient superoxide dismutase activity are ameliorated by $\mathrm{Zn}$ addition in maize roots [26], but it remains unclear why this disturbed reactive oxygen detoxification under $-\mathrm{Zn}$ is not compensated by gene up-regulation of other detoxification enzymes that do not require $\mathrm{Zn}$. In several species, the inability to maintain copper/zinc-dependent superoxide dismutase activity under $\mathrm{Zn}$ deficiency was 


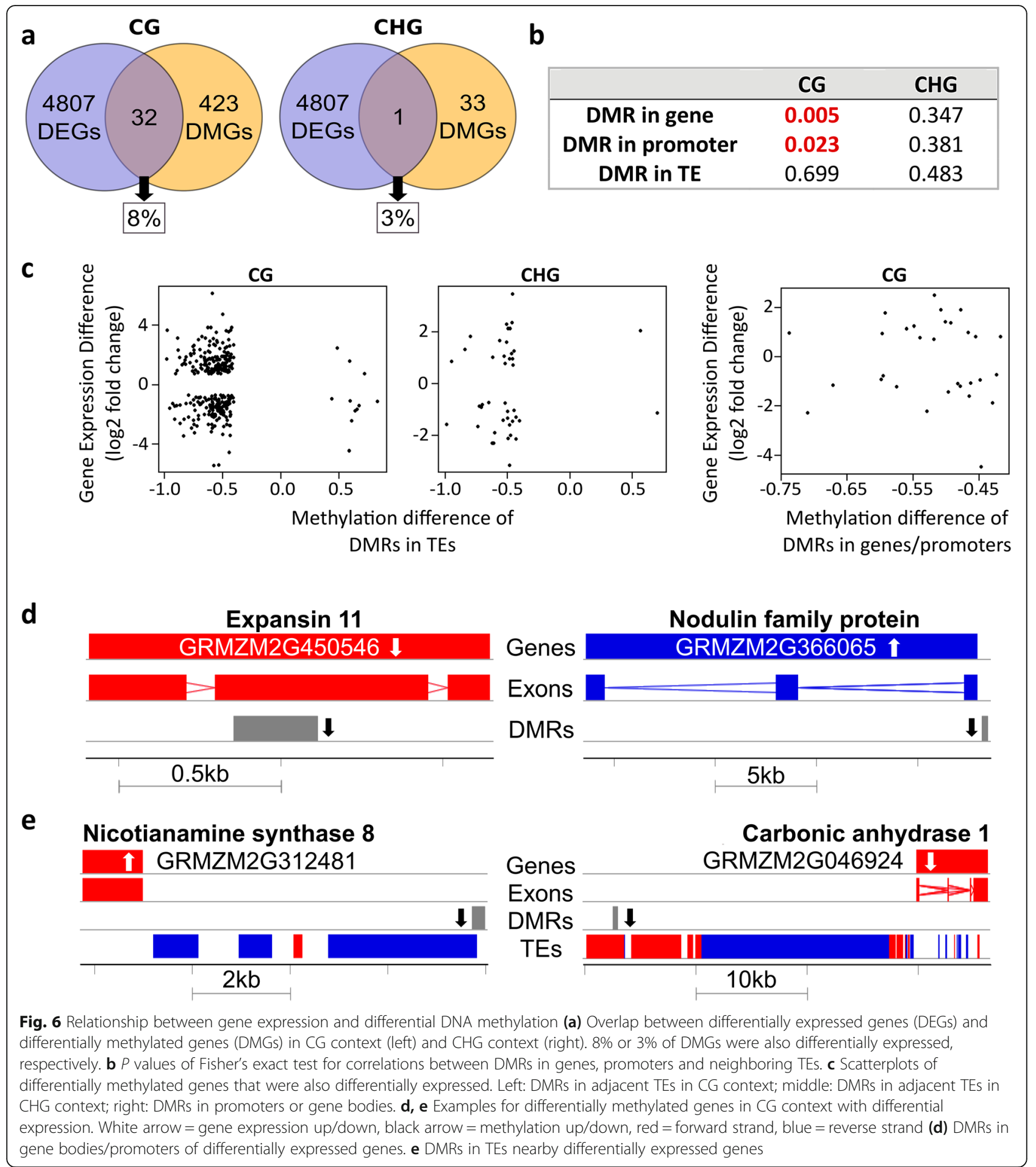

not compensated by an up-regulation of other reactive oxygen pathways [3], which results in increased superoxide and hydrogen peroxide concentrations in the root tissue. Interestingly, it is well-established that $\mathrm{Zn}$-deficient plants accumulate carbohydrates in their shoots, especially in the phloem sap of source leaves, but it was unclear whether this resulted from impaired phloem export of sucrose or decreased sink demand [3]. The finding that SWEET13 sucrose channel genes were exceptionally up-regulated in roots may indicate that the plants invest heavily in sucrose efflux in roots. These efflux channels may then also be involved in the increased root sugar exudation typically found under $\mathrm{Zn}$ deficiency [3]. 
We also noted a tendency for reduced expression of genes involved in methylation maintenance. The transcriptional response to prolonged $\mathrm{Zn}$ deficiency affected many more genes than in Arabidopsis, but key components of the $-\mathrm{Zn}$ deficiency response were highly similar $[7,27]$.

\section{Deficiency-adapted methylome}

Starting with the observation that methylation maintenance genes were suppressed under $-\mathrm{Zn}$, we asked whether methylation was affected by $-\mathrm{Zn}$. Previous analysis in Arabidopsis indicated methylation differences upon - $\mathrm{Zn}$ in roots and a minor methylation loss [27].

In contrast to Arabidopsis, a very strong loss in methylation frequency, especially in the CG and CHG contexts, was encountered in maize. This reduction in overall methylation, especially in the CG context, went along with DMRs being mostly hypomethylated. 97\% of CG DMRs and 93\% of CHG DMRs had lower methylation in $-\mathrm{Zn}$ than in the control. Slight visual symptom differences among individual shoots reflected slight variable stress levels in individual plants, which was mirrored by some variation within the (pooled) replicates. The adaptation of the methylation may be directly related to the lack of $\mathrm{Zn}$ or rather linked to a general stress response. In rice under phosphate starvation, DMRs were preferentially associated with starvation associated genes and TEs in their vicinity [13]. The occurrence of typical $\mathrm{Zn}$-starvation-regulated differential gene expression hints at a $\mathrm{Zn}$-specific adaptation in maize. Additionally, methylation was significantly related to expression of some of the differentially expressed genes.

The de novo more flexible $\mathrm{CHH}$ methylation is commonly thought to respond faster to environmental conditions than the symmetric CHG and CG contexts, but to our surprise, the CG context was most affected, while the $\mathrm{CHH}$ context was barely methylated and only a negligible number of $\mathrm{CHH}$ DMRs were found. This is in contrast to phosphate-starved rice [13], even with loosened criteria for defining DMRs. Li et al., 2015 also recognized low methylation in the $\mathrm{CHH}$ context in maize and only very few DMRs in five different maize inbred lines, including B73, which was studied here. The same discovery has been made by Eichten et al., 2013 who also found very low $(<10 \%)$ methylation in the $\mathrm{CHH}$ context of the inbred lines B73 and Mo17. In Arabidopsis thaliana a similar low methylation level (1.7\%) in the $\mathrm{CHH}$ context was found (Law and Jacobsen, 2011), similar to the plants in our experiments (1.3\% in control plants). DNA methylation differences were recorded after 4 weeks in $-\mathrm{Zn}$, but changes might occur within days, as in phosphate-starved rice [13]. A time course of methylation changes during development and treatments would be informative to better understand the relationship of these changes.

\section{Interaction between DNA methylation and gene expression}

Genome wide DNA methylation changes upon nutrient-stresses and the correlations with gene expression have rarely been studied in other plants than rice or Arabidopsis thaliana. It is clear that possibly harmful activities of transposable elements are silenced by hypermethylation of transposons (Dowen et al., 2012; Slotkin and Martienssen, 2007; Tan, 2010; Tsaftaris et al., 2003; Yong-Villalobos et al., 2015). Methylation changes in transposons frequently affect the expression of adjacent genes (Lisch and Bennetzen, 2011; Mirouze and Vitte, 2014; Slotkin and Martienssen, 2007). These mechanisms are probably of less importance in Arabidopsis, as this plant has few transposons and low methylation. In maize with its $2.3 \mathrm{~Gb}$ giant genome that is full of TEs, genes are spread over large distances, as are gene regulatory sequences (Schnable et al., 2009; Tenaillon et al., 2011). Parallel representative bisulfate DNA sequencing and RNA-seq identified correlated changes in the methylome and transcriptome of maize roots and revealed a strong decrease in methylation. The percentage of up- and down-regulation of zinc deficiency-regulated DEGs was almost the same ( $\sim 50 \%$ each), which led to a significant repression of many gene categories in $-\mathrm{Zn}$, including reactive oxygen handling and cell wall categories. We could show that several of the genes containing a DMR in their promoter or gene body were associated with altered gene expression, in contrast to the situation in $\mathrm{P}$ and $\mathrm{N}$ deficiencies, where no clear correlation was found [22]. However, differential methylation in transposable elements had a significant effect on the expression of nearby genes in $\mathrm{P}$ and $\mathrm{N}$ deficiency, while this was not found for $\mathrm{Zn}$ deficiency. However, due to the large maize genome and the very long stretches of genomic DNA that may be involved in regulating genes in maize, we may have missed correlations with more distant regions. In rice, by contrast, hypermethylated TEs were often close to induced genes [13], while in Arabidopsis hypermethylation of TEs frequently leads to decreased expression of nearby genes [28-30]. In - Zn maize roots, most TEs were hypomethylated, but a similar number of closeby genes was up- or down-regulated. The same was observed for demethylated genes or promoters in - $\mathrm{Zn}$, their expression was inconsistently increased or decreased. Thus, the potential general role of hypermethylation on gene expression remains unclear. Rather, literature as well as our results suggest strong species- and nutrient-specific methylation and transcription adaptation. That methylation level in promoters and gene bodies is correlated with gene expression is 
further supported by our data, but it is impossible to deduce causality from these data.

Even though hypomethylation is typically accompanied by an increased expression of transposable elements, this was not supported by our dataset, although we need to note that TE expression was not explicitly focused on. While under nitrogen and phosphorus deficiencies the overall expression of TEs was at least moderately increased [22], their expression in - $\mathrm{Zn}$ was even slightly reduced (by $9 \%$ ).

Small RNAs are associated with DNA methylation especially in the $\mathrm{CHH}$ context (which was little methylated) and we noted a tremendous reduction in small RNA amount in - Zn samples. This may suggest further cross-talk between the different methylation pathways and implicates that loss of methylation under $-\mathrm{Zn}$ in maize comes along with a reduction in small RNA amount even though there was not much change encountered in the expression of enzymes involved in the RdDM pathway. However, the quantification and reduction in small RNAs using the BioAnalyzer has also to be taken with caution, as small RNA levels may be subject to artifacts such as RNA degradation and inaccurate length estimation.

\section{Methylation, other stresses and potential function}

Usually, genomic instability is attributed to DNA hypomethylation in plants, humans, animals and fungi [31-33]. It was also frequently assumed that adaptation to stress is brought about by increased genomic flexibility and instability as well as increased transposon activity [31, 34-36]. As our results show a massive loss of DNA methylation in maize roots due to $\mathrm{Zn}$ and nitrogen deficiency in maize [22], increased chromosome rearrangements might result from demethylation, beside direct regulation of gene expression. Only limited correlation between DNA methylation and gene expression is now frequently found [37] and conclusions about these correlations are often contradictory, which solidifies the assumption of an additional function of DNA hypomethylation.

The functions of DNA methylation in somatic tissues, such as roots or leaves, may be quite distinct from those in the germline, where DNA methylation as an epigenetic mechanism may contribute to transgenerational inheritance. The level of DNA methylation is important for regulation of TE activity, the frequency of recombination events as well as the occurrence of mutations [31, 34, 38]. As suggested previously for other stresses, controlled increase in chromosome rearrangements as well as increased activity of transposable elements might enhance adaptational processes to $-\mathrm{Zn}$ conditions [31, 34].

Not only genome-wide hypomethylation, but also local loss of methylation was found to increase rearrangement of genes. The hypomethylated genes were found to be resistance gene-like loci [39]. This hints at the ability of plants to highly control the occurrence of events caused by genomic instability for 'controlled' increase of genetic diversity, while balancing the associated risks coming along with genomic instability [34]. The strong global loss of DNA methylation and a particularly strong loss at the centromere and pericentromeric regions may be relevant in this context, as the activity of the TEs as well as crossovers at the centromeric region are usually suppressed by DNA methylation [40]. To avoid adverse effects of excess genome instability caused by hypomethylation (especially at the centromere, where crossovers might lead to chromosome breakage or loss [41]), also epigenetic factors other than DNA methylation might exert control to balance genomic instability. Thereby, global hypomethylation provides the ability for fast gene expression regulation and plasticity of the plants as well as controlled increases of genomic instability at certain locations. This assumption is substantiated by no overall increase of recombination frequency [40], but a global redistribution of these events due to hypomethylation, indicating interaction of different (epigenetic) mechanisms. It was even suggested that plants might be able to 'recruit' retrotransposons under stress conditions to foster evolution [42]. Under nitrogen and phosphorus deficiency in maize there was indeed an increase in the overall expression of TEs found [22]. The slight decrease in TE expression under $-\mathrm{Zn}$ might be due to the strong intensity of the stress or indicating stress-specific mechanisms.

Furthermore, plants exposed to ionizing irradiation stress were hypermethylated [35]. The authors suspected that hypermethylation in these plants prevents excess genomic instability induced by radiation but still propose mutations and recombination as contributing mechanism by which plants adapted to the radiation stress. Similarly, a general hypermethylation in progeny of virus-infected tobacco plants with local hypomethylation increased frequency of recombination events [34]. Hypermethylation was also found in tobacco due to osmotic stress [38]. However, cold stress induced hypomethylation in maize roots [43] and heavy metal stress was shown to cause hypomethylation in hemp and clover [44].

Though there is only limited evidence for the heritability of changes in genome stability due to DNA methylation changes, some researchers reported increased recombination in at least the direct progeny of stress-exposed plants [34, 35, 39]. Additionally, changes in genome stability can not only be inherited meiotically, but also mitotically [34]. Thereby it can enhance genetic diversity by vegetative reproduction, e.g. by somatic recombination events [45], providing the chance for 
increased adaptation and plasticity especially on the population level in plants.

To verify the conclusion that the strong loss of DNA methylation not only influences gene expression but also plays a role in fostering genetic diversity by controlled increase in recombination and mutation frequencies, further experiments will be necessary.

DNA methylation loss might function in increasing overall plasticity and reactivity of plants under stress, as well as increasing genomic instability. Other epigenetic mechanisms, like histone modifications, might balance the effects of methylation loss by inhibiting excess chromosome rearrangements. Therefore, simultaneous investigation of DNA methylation as well as histone modifications might give a clearer picture of the different factors influencing gene expression regulation and adaptation strategies and the fine-tuning of genomic instability.

Another important aspect to be tested is the heritability of such adaptations. To consider meiotic heritability, generative cells, like pollen, should be investigated for methylome changes and frequency of recombination events as well as tissues of the F1 generation of stressed parents (e.g. endosperm and embryo). Mitotic heritability could be tested in plants that frequently propagate through vegetative reproduction.

The importance of increased genomic instability as evolutionary driver could be especially important on the population level. Hereby, the genetic diversity in (wild) plants grown on deficiency soils or on fully supplied soils could be compared by looking for differences in methylome and transcriptome data and investigating if the stressed population shows new traits or differences in genes important for stress response. Furthermore, the influence of stress-type, stress-intensity and species on recombination events, double-strand breaks or transposable element activity should be tested.

\section{Conclusions}

This work substantiates that DNA methylation changes in roots under nutrient deficiency. This is associated with gene expression changes that are related in nutrient-, species- and potentially organ-specific ways. How this affects the plasticity of the plants and functions as evolutionary driver by speeding up the development of new, potentially beneficial traits, should be tested in more detail in the future. The fact that different nutrient deficiencies (including macro- and micronutrients) resulted in methylation loss (though to a different extent) in maize roots, stimulates ideas for a range of further experiments. These could not only promote understanding of population genomics and aid evolutionary studies. As recombination is important to introduce new desired traits into plants during breeding, knowledge about plant-intern mechanisms altering recombination and TE activity through methylation changes could be artificially induced during breeding, enhancing velocity of the breeding processes, but it is required that the methylation in the germline responds similarly as somatic tissues to such stimuli $[46,47]$.

\section{Materials and methods \\ Plant growth and sampling}

Seeds of the inbred line B73 of Zea mays (from Dr. Schipprack of the department of Plant Breeding, University of Hohenheim) were first surface-sterilized with a $10 \% \mathrm{H}_{2} \mathrm{O}_{2}$ solution by rinsing them for $2 \mathrm{~min}$ and removing $\mathrm{H}_{2} \mathrm{O}_{2}$ by washing the seeds in distilled water. For $24 \mathrm{~h}$, the seeds were incubated in a $10 \mathrm{mM} \mathrm{CaSO}_{4}$ solution and were then put between foam sheets soaked in $3 \mathrm{mM} \mathrm{CaSO}{ }_{4}$ solution for 4 days for germination. Afterwards, they were set into $2.8 \mathrm{~L}$ of a nutrient solution containing $0.1 \mathrm{mM} \mathrm{K}_{2} \mathrm{SO}_{4}, 0.12 \mathrm{mM} \mathrm{MgCl}, 0.5 \mathrm{mM}$

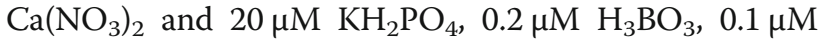
$\mathrm{MnSO}_{4}, 0.1 \mu \mathrm{M} \quad \mathrm{ZnSO}_{4}, 0.04 \mu \mathrm{M} \quad \mathrm{CuSO}_{4}$ and $2 \mathrm{nM}$ $\left(\mathrm{NH}_{4}\right)_{6} \mathrm{Mo}_{7} \mathrm{O}_{24}$. After 3 days, control plants were put on fully supplied maize hydroponic solution (2.8 $\mathrm{l})$ and $-\mathrm{Zn}$ plants on a modified, $\mathrm{Zn}$-deficient solution. The solution for control plants contained $0.5 \mathrm{mM} \mathrm{K}_{2} \mathrm{SO}_{4}, 0.6 \mathrm{mM}$

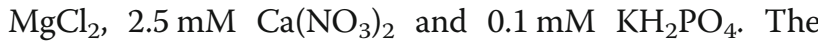
latter was raised to $0.2 \mathrm{mM}$ in the 3rd treatment week

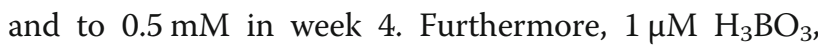
$0.5 \mu \mathrm{M} \mathrm{MnSO}_{4}, 0.5 \mu \mathrm{M} \mathrm{ZnSO}_{4}, 0.2 \mu \mathrm{M} \mathrm{CuSO}_{4}, 0.01 \mu \mathrm{M}$ $\left(\mathrm{NH}_{4}\right)_{6} \mathrm{Mo}_{7} \mathrm{O}_{24}$ and $100 \mu \mathrm{M}$ Fe-Sequestrene were added. This was raised to $200 \mu \mathrm{M}$ during the first nutrient solution change and from the second solution change on it stayed at $300 \mu \mathrm{M}$. Zn deficient plants were treated the same, except for the following modifications: The amount of $\mathrm{KH}_{2} \mathrm{PO}_{4}$ was not raised, but kept at $0.1 \mathrm{mM}$. Instead of Fe-Sequestrene, $300 \mu \mathrm{M}$ of Fe-EDTA were added to the solution, in case that Fe-Sequestrene contained traces of $\mathrm{Zn}$. Zn was omitted from the solution, but a residual $\mathrm{Zn}$ in the sub- $\mu \mathrm{M}$ range was always detected in the nutrient solution, probably resulting from the plastic containers in which the plants were grown. At week 3 and 4 of the treatment, $0.1 \mu \mathrm{M} \mathrm{ZnSO}_{4}$ were given to the solution for $24 \mathrm{~h}$ to prevent dying of the plants. Nutrient solution was exchanged once after one week and then every 3 days.

The plants grew in a climate chamber, enabling controlled growth conditions. A simulated day length of 16 $\mathrm{h}$ at $25^{\circ} \mathrm{C}$ and a night length of $8 \mathrm{~h}$ at $20^{\circ} \mathrm{C}$ was applied. Photosynthetically active photon flux density (PFD) was $400 \mu \mathrm{mol} \mathrm{m}^{-2} \mathrm{~s}^{-1}$ and humidity was kept at $60-80 \%$. For each condition 6 plants were grown, with 2 plants per pot. After 5 weeks (corresponding to 4 weeks of treatment), root and shoot material was harvested, whereby the two plants in one pot were pooled, resulting in 3 
replicates (with 2 plants per replicate) for both control and $-\mathrm{Zn}$.

\section{Nutrient analysis}

Leaf samples were ground to a fine powder before being digested in a microwave oven. Zinc, iron, phosphorus and nitrogen concentrations were measured. The latter three were measured to confirm nutrient specificity in -Zn samples. Zinc and iron were determined via inductively coupled plasma mass spectrometry (ICP-MS), while phosphorus was measured as orthophosphate after addition of molybdate-vanadate reagent via UV-VIS spectroscopy and nitrogen measurement was done after Kjeldahl [48].

\section{RNA sequencing on total RNA samples and transcriptome analysis}

Total RNA was extracted from root material of control and $-\mathrm{Zn}$ plants via the analytikjena innuPREP Plant RNA Kit, according to the manufacturer's manual. The quantity and quality of the RNA were checked with the Thermo Scientific Nanodrop 2000c Spectrophotometer and the Agilent 2100 Bioanalyzer. All RNA samples had a purity of OD260/280 $\geq 1.8$. A Truseq 160 basepair (bp) short-insert library and 100 bp paired-end sequencing on Hiseq4000 were made at the Beijing Genomics Institute (BGI, China). The clean data were quality checked via the FastQC tool version 0.11.5 (by Babraham Bioinformatics) and reads were aligned to the Zea mays reference genome (AGPv3), provided by the maizeGDB (Maize Genetics and Genomics Database) [49], with the options --phred64, --dta-cufflinks, --no-mixed and --no-discordant. Annotation files AGPv3 were used [49]. The assembly was done with cufflinks from the cufflinks suite of tools version 2.2.1 [50] with default options and the --GTF-guide and --no-effective-length-correction. After merging the assemblies with cuffmerge (with -g and -s options), cuffdiff was used to find differentially expressed genes (DEGs) with --compatible-hits-norm, $-\mathrm{b},-\mathrm{u}$ and otherwise default options. Transcript amounts are given as fragments per kilobase of transcript per million mapped reads (FPKM). Differences between the conditions are given as $\log _{2}$-fold changes as $\log _{2}\left(\mathrm{FPKM}_{-\mathrm{Zn}} / \mathrm{FPKM}_{\text {Control }}\right)$. The threshold for differentially expressed genes (after Benjamini-Hochberg correction for multiple testing) was set to $p<0.05$. Overrepresentation of differentially expressed gene categories was determined by a Parametric Analysis of Gene Set Enrichment (PAGE) using the reference genome Zea mays AGPv3.30 and the agriGO analysis toolkit version 1.2 [51]. Bonferroni multi-test adjusted values with different expression $(\mathrm{p}<0.05)$ were used.

\section{Reduced representation bisulfite sequencing of DNA} samples and methylome analysis

After harvest of the maize roots, the material was ground to a fine powder and the DNA was extracted via Qiagen DNeasy Plant Mini Kit according to the manual. DNA samples were checked for quantity and quality via Thermo Scientific Nanodrop 2000c Spectrophotometer and Qubit Fluorometric Quantitation. Only samples with an OD260/ 280 bigger or equal to 1.8 were used for further processing. The DNA was digested with MspI followed by selection of fragments between 40 to $220 \mathrm{bp}$. These fragments were used to construct a reduced representation bisulfite sequencing library. $100 \mathrm{bp}$ paired-end sequencing on Illumina Hiseq2000 was done at Beijing Genomics Institute (BGI, China). A quality checks of the clean data were done with FastQC version 0.11.5 (Babraham Bioinformatics). To increase the quality further, FastX-Toolkit version 0.0 .13 by Hannon Lab was used to cut off the first 4 and 6 last bp of all reads. Mapping was done via BS-Seeker2 version 2.0.10 [52] using the Zea mays reference genome AGPv3. BS-Seeker2 virtually cuts this genome with MspI and size-selects sequences of desired length. Parameters used were $-120,-\mathrm{u} 400,-$-aligner = bowtie 2 and otherwise default options. By virtually digesting the reference maize genome with MspI and subsequent size-selection of DNA fragments between 40 and $220 \mathrm{bp}$ length, the theoretically covered genome fraction (14\%) was determined. A broader range of size-selection (namely 20-400 bp length) than that for the digested DNA samples was used for the virtual reduced representation genome to account for inaccuracies during size-selection of the digested DNA samples. The bowtie2 as short read mapper and default settings were used for alignment and methylation calls [53]. DMRcaller version 1.2.0 [54] in $\mathrm{R}$ version 3.2.4 was used to determine differentially methylated regions (DMRs) by pooling the methylation level information from all three replicates. Smoothing was done via noise_filter with triangular kernel [55] for computing differentially methylated cytosines. DMRs were characterized between 50 and $500 \mathrm{bp}$, containing at least 4 cytosines (with at least 4 reads per cytosine), resulting in a methylation difference of at least $40 \%$ in comparison to the control and a $p$-value $<0.01$. DMRs located within genes were determined with gene information taken from maize annotation files in AGPv3 [49]. The region comprising $2000 \mathrm{bp}$ upstream of a gene was defined as a gene promoter. Transposable elements (TEs) annotation from the Unité de Recherche Génomique Info [56] was used.

\section{Correlating transcriptome data with methylation information}

Correlations between differential methylation in genes, promoters or TEs with gene expression were investigated 
by Fisher's exact test on a $2 \times 2$ contingency table in $\mathrm{R}$ version 3.3.3. Only genes covered by at least 500 bp by the reduced representation genome were taken into account for quantification of differentially methylated genes, promoters and their gene expression, to avoid false negative results. More distant (the closest) TEs were taken into account if they were covered by the reduced representation genome to avoid loss of very short transposable elements. BEDTools version 2.26.0 [57] was used to determine the closest gene to each transposon, regardless of being upstream or downstream.

\section{Quantification of small RNAs}

Small RNA was extracted from the same root material that was used for total RNA and DNA extractions. The extraction was done according to the analytikjena innuPREP Micro RNA Kit Manual. The samples were tested in the Thermo Scientific Nanodrop 2000c Spectrophotometer for purity and only samples with OD260/280 $\geq$ 2.0 were used. The amount of small RNAs was determined in the Agilent 2100 Bioanalyzer according to the Agilent Small RNA Kit Guide by Agilent Technologies. The ratio between the amount of sRNAs (15-30 nt length) and the total amount of RNA was determined. As 21-24 nt sRNAs are involved in the RdDM pathway, the 15-30 nt sRNA range was chosen to make sure that all 21-24 nt sRNAs were taken into account. Significant changes in the amount of sRNAs were determined via one-way ANOVA in R version 3.1.1.

\section{Additional file}

Additional file 1: Table S1. Alignment rate of RNA-Sequencing. Alignment rates were lower in $-\mathrm{Zn}$. Values are averaged among replicates. Figure S1. Cytosine coverage in CG, CHG and CHH contexts. Higher cytosine coverage in each context is observed under -Zn. Table S2. Alignment output of RRBS libraries. Similar mappability in control and -Zn of RRBS libraries. Values are averaged among replicates and shown in millions.

\section{Abbreviations}

DEG: differentially expressed gene; DMR: differentially methylated region; RdDM: RNA dependent DNA methylation; RRBS: reduce representation bisulfate sequencing; TE: transposable element; $\mathrm{Zn}$ : zinc

\section{Acknowledgements}

We thank Professor A. Melchinger and Dr. Schipprack of the department of Plant Breeding, University of Hohenheim, Stuttgart, for providing B73 seeds. Appreciation also goes to the staff of the department of Nutritional Crop Physiology, University of Hohenheim, Stuttgart. This work was supported by the Ministry for Science, Research and Art of Baden-Wuerttemberg (Az: 7533$30-20 / 1)$.

\section{Funding}

We thank the Ministry of Science Research and Arts Baden-Württemberg in the Regio-Research-Alliance "Yield stability in dynamic environments" for funding. The funding body was not involved in the design of the study and collection, analysis, interpretation of data and writing the manuscript.
Availability of data and materials

The raw data were submitted to NCBI and are available under the following accession: SAMN09464306.

\section{Authors' contributions}

SM and UL contributed to the conception and design of the study. SM performed the experiments and statistical analysis and wrote the first draft of the manuscript. UL wrote sections of the manuscript. BS contributed to the data analysis. All authors contributed to the manuscript revision, read and approved the submitted version.

\section{Ethics approval and consent to participate}

Not applicable.

\section{Consent for publication \\ Agreed.}

\section{Competing interests}

The authors declare that they have no competing interests.

\section{Publisher's Note}

Springer Nature remains neutral with regard to jurisdictional claims in published maps and institutional affiliations.

Received: 16 August 2018 Accepted: 12 December 2018

Published online: 27 December 2018

\section{References}

1. Broadley MR, White PJ, Hammond JP, Zelko I, Lux A. Zinc in plants. New Phytol. 2007;173:677-702.

2. Assuncao AG, Herrero E, Lin YF, Huettel B, Talukdar S, Smaczniak C, et al. Arabidopsis thaliana transcription factors bZIP19 and bZIP23 regulate the adaptation to zinc deficiency. Proc Natl Acad Sci U S A. 2010;107:10296-301.

3. Cakmak I. Possible role of zinc in protecting plant cells from damage by reactive oxygen species. New Phytol. 2000;146:185-205.

4. Yamaji N, Xia J, Mitani-Ueno N, Yokosho K, Feng Ma J. Preferential delivery of zinc to developing tissues in rice is mediated by P-type heavy metal ATPase OsHMA2. Plant Physiol. 2013;162:927-39.

5. Nielsen FH. History of zinc in agriculture. Adv Nutr. 2012;3:783-9.

6. Mattiello EM, Ruiz HA, Neves JC, Ventrella MC, Araujo WL. Zinc deficiency affects physiological and anatomical characteristics in maize leaves. J Plant Physiol. 2015;183:138-43.

7. van de Mortel JE, Almar Villanueva L, Schat H, Kwekkeboom J, Coughlan S, Moerland PD, et al. Large expression differences in genes for iron and zinc homeostasis, stress response, and lignin biosynthesis distinguish roots of Arabidopsis thaliana and the related metal hyperaccumulator Thlaspi caerulescens. Plant Physiol. 2006;142:1127-47.

8. Grotz N, Fox T, Connolly E, Park W, Guerinot ML, Eide D. Identification of a family of zinc transporter genes from Arabidopsis that respond to zinc deficiency. Proc Natl Acad Sci U S A. 1998;95:7220-4.

9. Li S, Zhou X, Huang Y, Zhu L, Zhang S, Zhao Y, et al. Identification and characterization of the zinc-regulated transporters, iron-regulated transporter-like protein (ZIP) gene family in maize. BMC Plant Biol. 2013;13:114

10. Khatun MA, Hossain MM, Bari MA, Abdullahil KM, Parvez MS, Alam MF, et al. Zinc deficiency tolerance in maize is associated with the up-regulation of Zn transporter genes and antioxidant activities. Plant Biol (Stuttg). 2018;20:765-70.

11. Mocchegiani E, Romeo J, Malavolta M, Costarelli L, Giacconi R, Diaz LE, et al. Zinc: dietary intake and impact of supplementation on immune function in elderly. Age (Dordr). 2013;35:839-60.

12. Prasad AS. Zinc in human health: effect of zinc on immune cells. Mol Med. 2008:14:353-7.

13. Secco D, Wang C, Shou H, Schultz MD, Chiarenza S, Nussaume L, et al. Stress induced gene expression drives transient DNA methylation changes at adjacent repetitive elements. elife. 2015;4:e09343.

14. Yong-Villalobos L, Gonzalez-Morales SI, Wrobel K, Gutierrez-Alanis D, Cervantes-Perez SA, Hayano-Kanashiro C, et al. Methylome analysis reveals an important role for epigenetic changes in the regulation of the Arabidopsis response to phosphate starvation. Proc Natl Acad Sci U S A. 2015;112:E7293-302. 
15. Lewsey MG, Hardcastle TJ, Melnyk CW, Molnar A, Valli A, Urich MA, et al. Mobile small RNAs regulate genome-wide DNA methylation. Proc Natl Acad Sci U S A. 2016;113:E801-10.

16. Rogers K, Chen X. Biogenesis, turnover, and mode of action of plant microRNAs. Plant Cell. 2013;25:2383-99.

17. Wu L, Zhou H, Zhang Q, Zhang J, Ni F, Liu C, et al. DNA methylation mediated by a microRNA pathway. Mol Cell. 2010;38:465-75.

18. Pikaard CS, Mittelsten Scheid O. Epigenetic regulation in plants. Cold Spring Harb Perspect Biol. 2014;6:a019315.

19. Vidalis A, Zivkovic D, Wardenaar R, Roquis D, Tellier A, Johannes F. Methylome evolution in plants. Genome Biol. 2016;17:264

20. Bharti K, Pandey N, Shankhdhar D, Srivastava PC, Shankhdhar SC. Effect of different zinc levels on activity of superoxide dismutases \& acid phosphatases and organic acid exudation on wheat genotypes. Physiol Mol Biol Plants. 2014;20:41-8

21. Bezrutczyk M, Hartwig T, Horschman M, Char SN, Yang J, Yang B, et al. Impaired phloem loading in zmsweet13a,b,c sucrose transporter triple knock-out mutants in Zea mays. New Phytol. 2018;218:594-603.

22. Mager S, Ludewig U. Massive loss of DNA methylation in nitrogen-, but not in phosphorus-deficient Zea mays roots is poorly correlated with gene expression differences. Front Plant Sci. 2018:9:497.

23. Wolfgruber TK, Sharma A, Schneider KL, Albert PS, Koo DH, Shi J, et al. Maize centromere structure and evolution: sequence analysis of centromeres 2 and 5 reveals dynamic loci shaped primarily by retrotransposons. PLoS Genet. 2009:5:e1000743.

24. Broadley M, Brown P, Cakmak I, Rengel Z, Zhao F. Function of Nutrients: Micronutrients. In: Marschner's Mineral Nutrition of Higher Plants. 3rd ed; 2011. p. 212-22.

25. Randall PJ, Bouma D. Zinc deficiency, carbonic anhydrase, and photosynthesis in leaves of spinach. Plant Physiol. 1973;52:229-32.

26. Moradtalab N, Weinmann M, Walker F, Hoglinger B, Ludewig U, Neumann $\mathrm{G}$. Silicon improves chilling tolerance during early growth of maize by effects on micronutrient homeostasis and hormonal balances. Front Plant Sci. 2018;9:420.

27. Chen X, Schonberger B, Menz J, Ludewig U. Plasticity of DNA methylation and gene expression under zinc deficiency in Arabidopsis roots. Plant Cell Physiol. 2018:59:1790-802.

28. Ahmed I, Sarazin A, Bowler C, Colot V, Quesneville H. Genome-wide evidence for local DNA methylation spreading from small RNA-targeted sequences in Arabidopsis. Nucleic Acids Res. 2011:39:6919-31.

29. Eichten SR, Ellis NA, Makarevitch I, Yeh CT, Gent JI, Guo L, et al. Spreading of heterochromatin is limited to specific families of maize retrotransposons. PLoS Genet. 2012:8:e1003127.

30. Hollister JD, Gaut BS. Epigenetic silencing of transposable elements: a tradeoff between reduced transposition and deleterious effects on neighboring gene expression. Genome Res. 2009;19:1419-28.

31. Iwasaki M, Paszkowski J. Epigenetic memory in plants. EMBO J. 2014;33: 1987-98.

32. Mirouze M, Reinders J, Bucher E, Nishimura T, Schneeberger K, Ossowski S, et al. Selective epigenetic control of retrotransposition in Arabidopsis. Nature. 2009;461:427-30.

33. Putiri EL, Robertson KD. Epigenetic mechanisms and genome stability. Clin Epigenetics. 2011;2:299-314.

34. Boyko A, Kathiria P, Zemp FJ, Yao Y, Pogribny I, Kovalchuk I. Transgenerational changes in the genome stability and methylation in pathogen-infected plants: (virus-induced plant genome instability). Nucleic Acids Res. 2007;35:1714-25.

35. Kovalchuk I, Abramov V, Pogribny I, Kovalchuk O. Molecular aspects of plant adaptation to life in the Chernobyl zone. Plant Physiol. 2004;135:357-63.

36. Molinier J, Ries G, Zipfel C, Hohn B. Transgeneration memory of stress in plants. Nature. 2006:442:1046-9.

37. Roessler K, Takuno S, Gaut BS. CG methylation Covaries with differential gene expression between leaf and floral bud tissues of Brachypodium distachyon. PLoS One. 2016;11:e0150002.

38. Labra M, Ghiani A, Citterio S, Sgorbati S, Sala F, Vannini C, et al. Analysis of cytosine methylation pattern in response to water deficit in pea root tips. Plant Biol. 2002;4:694-9.

39. Boyko A, Blevins T, Yao Y, Golubov A, Bilichak A, Innytskyy Y, et al. Transgenerational adaptation of Arabidopsis to stress requires DNA methylation and the function of dicer-like proteins. PLoS One. 2010;5:e9514.
40. Mirouze M, Lieberman-Lazarovich M, Aversano R, Bucher E, Nicolet J, Reinders J, et al. Loss of DNA methylation affects the recombination landscape in Arabidopsis. Proc Natl Acad Sci U S A. 2012;109:5880-5.

41. Talbert PB, Henikoff S. Centromeres convert but don't cross. PLoS Biol. 2010;8:e1000326.

42. Mirouze M, Vitte C. Transposable elements, a treasure trove to decipher epigenetic variation: insights from Arabidopsis and crop epigenomes. J Exp Bot. 2014;65:2801-12.

43. Steward N, Ito M, Yamaguchi Y, Koizumi N, Sano H. Periodic DNA methylation in maize nucleosomes and demethylation by environmental stress. J Biol Chem. 2002:277:37741-6.

44. Aina R, Sgorbati S, Santagostino A, Labra M, Ghiani A, Citterio S. Specific hypomethylation of DNA is induced by heavy metals in white clover and industrial hemp. Physiol Plant. 2004;121:472-80.

45. Boyko A, Kovalchuk I. Genome instability and epigenetic modification-heritable responses to environmental stress? Curr Opin Plant Biol. 2011;14:260-6.

46. Gutzat R, Mittelsten Scheid O. Epigenetic responses to stress: triple defense? Curr Opin Plant Biol. 2012;15:568-73.

47. Pan Q, Deng M, Yan J, Li L. Complexity of genetic mechanisms conferring nonuniformity of recombination in maize. Sci Rep. 2017;7:1205.

48. Kjeldahl J. Neue Methode zur Bestimmung des Stickstoffs in organischen Körpern. J Analyt Chem. 1883;22:366-82.

49. Sen TZ, Andorf CM, Schaeffer ML, Harper LC, Sparks ME, Duvick J, et al. MaizeGDB becomes 'sequence-centric. Database. 2009;bap020:1-9.

50. Trapnell C, Williams BA, Pertea G, Mortazavi A, Kwan G, van Baren MJ, et al. Transcript assembly and quantification by RNA-Seq reveals unannotated transcripts and isoform switching during cell differentiation. Nat Biotechnol. 2010;28:511-5.

51. Du Z, Zhou X, Ling Y, Zhang Z, Su Z. agriGO: a GO analysis toolkit for the agricultural community. Nucleic Acids Res. 2010;38:W64-70.

52. Guo W, Fiziev P, Yan W, Cokus S, Sun X, Zhang MQ, et al. BS-Seeker2: a versatile aligning pipeline for bisulfite sequencing data. BMC Genomics. 2013;14:774

53. Langmead B, Salzberg SL. Fast gapped-read alignment with bowtie 2 . Nat Methods. 2012;9:357-9.

54. Zabet N, Tsang J. DMRcaller: differentially methylated regions caller. $\mathrm{R}$ package version 1.6.0. 2015. Bioconductor: www.bioconductor.org.

55. Hebestreit K, Dugas M, Klein HU. Detection of significantly differentially methylated regions in targeted bisulfite sequencing data. Bioinformatics. 2013;29:1647-53.

56. Jamilloux V, Daron J, Choulet F, Quesneville H. De novo annotation of transposable elements: tackling the fat genome issue. Proc IEEE. 2017;105:474-81.

57. Quinlan AR, Hall IM. BEDTools: a flexible suite of utilities for comparing genomic features. Bioinformatics. 2010;26:841-2.
Ready to submit your research? Choose BMC and benefit from:
- fast, convenient online submission
- thorough peer review by experienced researchers in your field
- rapid publication on acceptance
- support for research data, including large and complex data types
- gold Open Access which fosters wider collaboration and increased citations
- maximum visibility for your research: over $100 \mathrm{M}$ website views per year
At $\mathrm{BMC}$, research is always in progress.
Learn more biomedcentral.com/submission 